\title{
Türkiye'de Bazı Yabani Memelilerde Bulunan Dış Parazit Türlerinin İlk Kayıtları
}

\author{
Ahmet Onur Girişgin ${ }^{1^{*}}$, Nurgül Çimenlikaya ${ }^{1}$, S. Ali Bah ${ }^{1}$, \\ Levent Aydın', Oya Girişgin ${ }^{2}$ \\ ${ }^{1}$ Uludağ Üniversitesi Veteriner Fakültesi, Parazitoloji Anabilim Dalı, Bursa, Türkiye \\ ${ }^{2}$ Uludağ Üniversitesi Karacabey Meslek Yüksekokulu, Bursa, Türkiye
}

Gönderilme: 13.03.2018 Kabul: 15.05.2018

\begin{abstract}
Özet
Dış parazitler memeli, kanatlı ve sürüngenleri enfeste eden, birçok hastalığa vektörlük yapan veya yaşam kalitesini düşüren etkenlerdir. Bu çalışmada, Anabilim Dalımız laboratuvarına getirilen dış parazit örneklerinin teşhislerinin konarak muhtemel yeni kayıtların varlığı araştırılmıştır. Tümü ülkemiz sınırları içerisinde bulunan, dördü esaret altında toplam yedi yabani memeli hayvandan örnekler toplanmıştır. Getirilen örnekler \%70’lik etanol içerisine alınıp kuralına uygun şekilde preparat yapıldıktan sonra veya direk mikroskop altında incelenerek tür teşhisleri yapılmıştır. Örneklerin muayenesi sonucu boz ayıda Haemaphysalis erinacei; kızıl geyikte Lipoptena cervi; aslan, kaplan ve çizgili sırtlanda Rhipicephalus sanguineus; Anadolu sincabında Nosopsyllus fasciatus türü dış parazitler belirlenmiştir. Elde edilen veriler ve yapılan araştırmalar sonucu, bulunan tüm parazit türlerinin daha önce T ürkiye’de bildirilmelerine rağmen, bu hayvanlardan ilk defa bulundukları tespit edilmiştir. Türkiye’de yabani memeli hayvanlardaki parazit türleriyle ilgili çalışmaların ve verilerin kısıtlı olması nedeniyle, Türkiye için yeni konak kayıtları olan bu türler bildirilmektedir.

Anahtar kelimeler: Yabani hayvan, memeli, dış parazit, Türkiye.
\end{abstract}

\section{Abstract \\ First records of some ectoparasites from wild mammals in Turkey}

Ectoparasites are the insects that infest mammalian, avian and reptilian hosts and play a role as vectors for numerous diseases or decrease the life quality. In this study, the existence of potential new records for ectoparasite samples brought to our laboratory was investigated. Ectoparasite samples were collected from totally seven wild mammals which three of them captive in Turkey. After all samples were kept in $70 \%$ ethanol for a day, they were identified under the light microscope with preparation slides or directly under the stereomicroscope.

Examination of the ectoparasite samples resulted as the species of Haemaphysalis erinacei from brown bear; Lipoptena cervi from red deer; Rhipicephalus sanguineus from lion, tiger and striped hyena; and Nosopsyllus fasciatus from Caucasian squirrel. As the result of data and prior investigations, all ectoparasite samples detected in this study have been before reported from Turkey. However, all these are the first host records for Turkish fauna. Because of the limited data and limited studies on the parasite species of wild mammals in Turkey, these ectoparasites are reported as new host records for Turkey.

Keywords: Wild animals, mammalian, ectoparasite, Turkey.

\section{Giriş}

Türkiye, farklı habitat tiplerine ve zengin bir hayvan varlığına sahiptir, ortalama 170 tür yabani memeli yaşamaktadır ve bunların da 128'i küçük memeliler olarak sınıflandırılmıştır (Şekercioğlu ve ark., 2011). Bazı yabani memelilerin iç-dış parazitlerine ait çalışmalar bulunmasına rağmen (Uslu ve ark, 2008; Açıcı ve ark, 2012, 2017), yabani memelileri enfeste eden dış parazitlere ait çalışmalar yetersizdir.

Yabani memelileri enfeste eden dış parazitler genel olarak bitler (Phthiraptera), pireler (Siphonaptera), keneler (Ixo- 
dida), uyuzlar - parazitik akarlar (Acari: Parasitiformes) ve sinekler (Culicidae, Ceratapogonidae, Psychodidae, Simuliidae, Tabanidae, Rhogionidae, Anthericidae, Cyclorrhapha, Muscoid sinekler, Oestridae, Hippoboscoidea) olarak ayrılabilir (İça ve ark, 2008). Söz konusu parazitlerin bir kısmının zoonotik özellik taşımalarından ve pek çok patojene rezervuarlık yapmalarından dolayı varlığının ve yaygınlığının bilinmesi önemlidir. Türkiye'de bu çalışmada bahsedilen memeli hayvanların dış parazitlerine ait iki kayıt bulunmaktadır Konyảda bir Anadolu sincabinda Neohaematopinus sciuri türü bit (Dik ve Yamaç, 2017) ve Van'da bir boz ayıda Trichodectes pinguis türü bit (Dik ve Kılınç, 2015) tespit edilmiştir. Kızıl geyik, aslan, kaplan veya çizgili sırtlana ait herhangi bir dış parazit kaydına rastlanmamıştır. Bu çalışmanın amacı, son üç yıl içinde tarafımıza getirilen, bu yabani memeli hayvanlarda şimdiye kadar kaydı bulunmayan dış parazitleri teşhis etmek ve yeni kayıtları ilgili literatüre eklemektir

\section{Materyal ve Metot}

Çalışmada belirtilen dış parazitlerin ait olduğu hayvan-lar, Uludağ Üniversitesi Veteriner Fakültesi Hayvan Hastanesine tedavi amaciyla getirilmiş veya yetkili kurumlar/ kişiler tarafından başka bir ilde muayeneleri yapılan ergin hayvanlardır. Bursa'da bulunan hayvanlardan; Anadolu sincabı kampüste öğrenciler tarafından baygın bir şekilde bulunarak hastaneye getirilmiş, boz ayı ise araba çarpması sonucunda hastaneye ulaştırılmıştır. Kızıl geyik Üniversite kampüsünde koruma alanında bulunan sürüye aittir. Diğer üç hayvan olan aslan, kaplan ve çizgili sırtlan, Gaziantep Hayvanat bahçesinde muayene edilmiştir. ayvanların başta kafa ve kulak olmak üzere diğer tüm vücut bölgeleri tüyleri aralanarak dış parazitler yönünden muayene edilmişlerdir. Görülen parazitler pensle toplanarak petri kaplarına alınmışlardır. Laboratuvara getirilen dış parazit numuneleri \% 70'lik al-kol içine alınmıştır. Kene ve sinek örnekleri direk olarak stereo mikroskop altında, pire örneği ise \%10'luk potas-yum hidroksitte bir gün şeffaflaştırılıp daha sonra alkol serilerinden geçirilip preparat haline getirildikten sonra ışı mikroskobu altında incelenmiştir. Parazitlerin tür teşhisleri ilgili literatürlerde belirtilen morfolojik kriterlere göre yapılmıştır (Smit, 1957; Hutson, 1984; Estrada-Pena ve ark., 2004).

\section{Bulgular}

Toplam 7 adet yabani hayvan dış parazitler yönünden incelenmiş ve tümü de enfeste bulunmuştur. Toplam 3 fark- lı diziden, 4 farklı tür, 39 adet dış parazit teşhis edilmiştir (Tablo 1). Boz ayıda Haemaphysalis erinacei (2,+ 6 đ) türü keneler (Acarina); aslanlar, kaplan ve çizgili sırtlanda Rhipicephalus sanguineus (13 +, $14 \hat{\jmath}, 1$ nimf) türü kene (Acarina); kızll geyikte Lipoptena cervi $(1+, 1 \precsim)$ türü sinek (Diptera); Anadolu sincabından ise Nosopsyllus fasciatus (1 + ) türü pire (Siphonaptera) teşhis edilmiştir.

Tablo 1. Konaklarına göre teşhis edilen parazit türleri

\begin{tabular}{|c|c|c|c|c|}
\hline $\begin{array}{c}\text { Konağın } \\
\text { Türkçe ismi }\end{array}$ & $\begin{array}{c}\text { Konağın } \\
\text { Latince ismi }\end{array}$ & $\begin{array}{c}\text { Bulunan } \\
\text { parazitin Dizi- } \\
\text { Ailesi }\end{array}$ & $\begin{array}{l}\text { Bulunan dış } \\
\text { parazit türü }\end{array}$ & Adet \\
\hline Boz ay1 & Ursus arctos & $\begin{array}{l}\text { Acarina: } \\
\text { Ixodidae }\end{array}$ & $\begin{array}{c}\text { Haemaphysalis } \\
\text { erinacei }\end{array}$ & 29,60 \\
\hline Kızıl geyik & $\begin{array}{l}\text { Cervus } \\
\text { elaphus }\end{array}$ & $\begin{array}{c}\text { Diptera: } \\
\text { Hippoboscidae }\end{array}$ & Lipoptena cervi & $1 \%, 1 \delta$ \\
\hline Aslan (2) & Panthera leo & $\begin{array}{l}\text { Acarina: } \\
\text { Ixodidae }\end{array}$ & $\begin{array}{l}\text { Rhipicephalus } \\
\text { sanguineus }\end{array}$ & $\begin{array}{l}8 \%, 10 \text { o, } 1 \mathrm{nimf} \\
\text { (Rhipicephalus spp.) }\end{array}$ \\
\hline Kaplan & $\begin{array}{c}\text { Panthera } \\
\text { tigris }\end{array}$ & $\begin{array}{l}\text { Acarina: } \\
\text { Ixodidae }\end{array}$ & $\begin{array}{l}\text { Rhipicephalus } \\
\text { sanguineus }\end{array}$ & 2 ㅇ, 3 ठ \\
\hline Çizgili surtlan & $\begin{array}{l}\text { Hyaena } \\
\text { hyaena }\end{array}$ & $\begin{array}{l}\text { Acarina: } \\
\text { Ixodidae }\end{array}$ & $\begin{array}{l}\text { Rhipicephalus } \\
\text { sanguineus }\end{array}$ & $3 \%, 10$ \\
\hline $\begin{array}{l}\text { Anadolu } \\
\text { sincab1 }\end{array}$ & $\begin{array}{l}\text { Sciurus } \\
\text { anomalus }\end{array}$ & $\begin{array}{l}\text { Siphonaptera: } \\
\text { Ceratophyllidae }\end{array}$ & $\begin{array}{l}\text { Nosopsyllus } \\
\text { fasciatus }\end{array}$ & 1 ㅇ \\
\hline
\end{tabular}

Aynı anda birden fazla tür diş parazitle enfeste hayvan olmamıştır. Tüm hayvanların erişkin yaşta oldukları görülmüştür. Kızıl geyik, aslan, kaplan ve çizgili sırtlan, Türkiye’de dış parazitler yönünden ilk defa muayene edilmişlerdir. Muayene edilen hayvanlarda bulunan tüm parazitler Türkiye'de bu hayvanlarda bulunan ilk kayıtlardır.

\section{Tartışma ve Sonuç}

Tirkiyede yabani memelilerin veya kuşların iç/dış parazitleri ile ilgili çeşitli çalışmalar bulunmaktadır. Her ne kadar bu çalışmalar yetersiz sayıda ise de, son yıllarda sayı artmaktadır. Bu çalışmada, doğada yaşayan veya esaret altında bulunan yabani memelilerde saptanan diş parazitler incelenmiştir.

Boz ayı (Ursus arctos) Türkiye'de yabani yaşamda en fazla bulunan karnivordur ve özellikle Karadeniz ve Doğu Anadolu Bölgelerinde daha fazla bulunmaktadır (Ambarlı ve ark., 2016). Çalışmada incelenen boz ayı Bursa’nın İnegöl ilçesinde yaralı olarak bulunmuştur. Ülkemizde daha önce sadece Van ilinde bir ayıda dış parazit incelemesi yapılmış olsa da bu incelemede Trichodectes pinguis bit türüne rastlanmış fakat keneye rastlanmamıştır (Dik ve Kılınç, 2015). Çalışmamızda ise Haemaphysalis erinacei türü kenelere rastlanmıştır. Bu tür keneler Türkiye'de daha 
önce tilki, kirpi ve Arap tavşanlarında bulunmuşken (Hoogstraal, 1959), bu çalışmayla bir boz ayıdan ilk defa bildirilmektedir. Anadolu sincabı (Sciurus anomalus), Türkiye'nin tüm bölgelerinde özellikle ağaçlar üzerinde yaşamaktadır (Albayrak ve Arslan, 2006). Çalışmada kullanılan sincap, Bursa'da Üniversite kampüsünde öğrenciler tarafindan bulunmuştur. Yapılan muayenede üzerinden Nosopsyllus fasciatus türü pire tespit edilmiştir. Türkiye'de aynı tür sincapların dış parazitleri ile ilgili tek veride, bulunan dış parazitin $N$. sciuri türü bir bit olduğu belirtilmiştir (Dik ve Yamaç, 2017). Bu yayınla N. fasciatus türü pire, Türkiye'de Anadolu sincaplarında ( $S$. anomalus) ilk defa bildirilmektedir. Kızıl geyikler Türkiye'de sınırlı alanlarda doğal olarak veya belli koruma alanlarında yaşayan ruminantlardır. Çalışmada kullanılan geyik, Bursa Uludağ Üniversitesi kampü-sü içerisinde bulunan koruma alanındaki kızıl geyiklerden biridir. Bu geyikten tespit edilen Lipoptena cervi sinekleri, Türkiye'de daha önce karacalarda tespit edilmiştir (Açıcı ve ark., 2012). Fakat Türkiye'de kızıl geyiklerin iç veya dış parazitleri ile ilgili bir çalışma bulunmamaktadır. Dolayısıyla bu çalışmada elde edilen $L$. cervi türü sinekler, Türkiye'de kızıl geyiklerden ilk defa bildirilmektedir. Çalışmada bulunan aslan, kaplan ve çizgili sırtlan, Gaziantep Hayvanat bahçesinde muayene edilmişlerdir. Türki-ye'de Hayvanat bahçelerinde tutulan memeli hayvanların enfeksiyon ve iç parazitleri ile ilgili bazı veriler olmasına rağmen, dış parazitlerine ait herhangi bir veri bulunma-maktadır. Böylelikle bu çalışmada tespit edilen Rhipicephalus sanguineus türü keneler, Türkiye'de esaret altında bulunan aslan, kaplan ve çizgili sırtlanlardan ilk defa bildirilmektedir. Türkiye'de memeli yaban hayvanlarının dış parazitleri hak-kında çok az bilgi bulunmaktadır. Yapılan bu çalışmayla teşhis edilen parazitler, konak hayvana göre ilk kayıtlar-dır. Bu sebeple Türkiye yaban hayatı faunası için değerli bir veri oluşturacaktır. Ülkemizdeki yaban hayvanlarının gerek iç gerekse dış parazitleri hakkında daha fazla bilgi sahibi olunması için, ileri ki yıllarda ilave araştırmalara ihtiyaç vardır.

\section{Teșekkür}

Bursa kaynaklı numuneleri Anabilim Dalımız laboratuvarına getiren Uludağ Üniversitesi Veteriner Fakültesi öğrencilerine, Gaziantep kaynaklı numuneleri laboratuvarımıza getiren Doç. Dr. Hüseyin Cihan'a teşekkür ederiz.

\section{Kaynaklar}

Açıcı M, Bölükbaş CS, Beyhan YE, Pekmezci GZ, Gürler AT, Umur Ş. Ectoparasites on roe deer (Capreolus capreolus) in Samsun, Turkey. Turk J Vet Anim Sci, 36(4): 456459, 2012.

Açıcı M, Demirtaş S, Umur Ş, Gürler AT, Bölükbaş CS. Infestations of flea species on small, wild mammals in the provinces of Aydın and Manisa in the Aegean Region, Turkey. Turk J Vet Anim Sci, 41(3): 449-452, 2017.

Ambarlı H, Ertürk A, Soyumert A. Current status, distribution, and conservation of brown bear (Ursidae) and wild canids (gray wolf, golden jackal, and red fox; Canidae) in Turkey. Turk J Zool, 40: 944-956, 2016.

Albayrak İ, Arslan A. Contribution to the taxonomical and biological characteristics of Sciurus anomalus in Turkey (Mammalia: Rodentia). Turk J Zool, 30: 111-116, 2006.

Dik B, Kılınç ÖO. First case of Trichodectes pinguis (Phthiraptera: Ischnocera: Trichodectidae) on a Bear (Ursus arctos) in Turkey. Türkiye Parazitol Derg, 39: 313-315, 2015.

Dik B, Yamaç E. Türkiye'deki yabani hayvanlarda görülen bit türleri (Phthiraptera, Ischnocera, Amblycera) üzerine araştırmalar. 20. Ulusal Parazitoloji Kongresi, 25 -29 Eylül 2017, Eskişehir. Özet kitabı sf. 335, 2017.

Estrada-Pena A, Bouattour A, Camicas JL, Walkwer A.Ticks of domestic animals in the Mediterranean region. Vol 131, Netherland. 2004.

Hoogstraal H. Biological observations on certain Turkish Haemaphysalis ticks (Ixodoidea-Ixodoidae). J Parasitol, 45(2): 227-232. 1959.

Hutson AM. Keds, flat-flies and bat-flies. Diptera, Hippoboscidae and Nycteribiidae - Handbooks for the Identification of British Insects, 10(7): 1-40. 1984.

İça A, İnci A, Yıldırım A, Düzlü Ö. Memelilerin (Yabani) Paraziter Hastalıklar1-II: Artropod Enfestasyonlar1. Erciyes Üniv Vet Fak Derg, 5(2): 93-106, 2008.

Smit FGAM. Siphonaptera. In. Handbooks for the Identification of British Insects. Vol. 1, Part 16. Royal Entomological Society of London, 94 p, 1957. 
Şekercioğlu ÇH, Anderson S, Akçay E ve ark. Turkey's globally important biodiversity in crisis. Biol Conserv, 144: 2752-2769, 2011.

Uslu U, Dik B, Gökçen A. Ectoparasites of the ground squirrel (Citellus citellus (L.)) in Turkey. Türkiye Parazitol Derg, 32: 142-145, 2008. 